\title{
Políticas linguísticas, internacionalização, novas tecnologias e formação docente: um estudo de caso sobre o curso de Letras Inglês em uma Universidade Federal
}

\section{KYRIA FINARDI}

Professora Doutora do Departamento de Linguagens, Cultura e Educação da UFES Universidade Federal do Espírito Santo; Programa Pós-Graduação em Linguística (PPGEL) e Programa Pós-Graduação em Educação (PPGE); Vitória; Espírito Santo; Brasil.

kyria.finardi@gmail.com

Resumo: Este estudo reflete sobre o ensino de inglês no Brasil contemporâneo tendo em vista as políticas linguísticas e de internacionalização da educação, e a formação tecnológica dos futuros professores de inglês. Para tanto, o estudo analisa a grade curricular, a ementa e a prática das disciplinas de estágio supervisionado de um curso de licenciatura em Letras Inglês de uma universidade federal brasileira. Os resultados sugerem que há uma tensão entre o papel formador e o papel instrumental do inglês, não contemplada de forma explícita por políticas linguísticas nem equacionada pelo curso de formação de professores de inglês analisado.

Palavras-chave: Políticas linguísticas; internacionalização; formação docente de professores de Inglês.

\section{Gicele Prebianca}

Professora Doutora do Instituto Federal de Educação, Ciência e Tecnologia Catarinense campus Blumenau; Blumenau; Santa Catarina; Brasil.

gicele.prebianca@blumenau.ifc.edu.br.

Abstract: This study reflects on the contemporary teaching of English in Brazil in face of linguistic and internationalization policies in teacher education for the use of technology. So as to do that, the study analyzes the program and practice of the teaching practicum course of an English teaching degree of a Brazilian federal university. The results suggest that there is a tension between the educational and instrumental roles of English not explicitly contemplated by national linguistic policies and the English teaching degree course investigated.

Key-words: Linguistic policies; internationalization; English teacher education. 



\section{Introdução}

A distância entre a teoria e a prática tem sido apontada como uma questão a ser repensada no sentindo de melhorar a educação em geral e o ensino de línguas em particular (MATEUS, 2009; FINARDI; DALVI, 2012). Assim, propomos a reflexão sobre teorias, políticas linguísticas e práticas pedagógicas a fim de formar profissionais autônomos (JOHNSON; FREEMAN, 2001). Nesse sentido, o estudo sugere que a lacuna apontada entre teoria e prática docente (FINARDI; DALVI, 2012) se estende às políticas linguísticas e ao ensino de línguas estrangeiras no Brasil contemporâneo, em especial no tocante à formação tecnológica ${ }^{1}$ do futuro docente e ao ensino de inglês como língua internacional (FINARDI; PREBIANCA; MOMM, 2013). ${ }^{2}$

Propomos a reflexão sobre o papel do inglês na atualidade por meio da análise qualitativa (i) de políticas linguísticas para o ensino de línguas estrangeiras no Brasil, (ii) da grade curricular de um curso de Licenciatura em Letras Inglês de uma universidade federal (UF) do sudeste brasileiro, (iii) das ementas e programas das disciplinas de estágio supervisionado I e estágio supervisionado II desse mesmo curso e (iv) das observações das aulas teóricas e práticas dessas disciplinas ao longo de um semestre letivo.

Tanto a reflexão quanto a análise dos documentos supracitados são motivadas por três questionamentos: $\mathrm{O}$ que dizem as políticas linguísticas para o ensino de língua estrangeira em geral e para o ensino de inglês especificamente no Brasil? $\mathrm{O}$ emprego das novas tecnologias é contemplado (de alguma forma) pelas políticas linguísticas vigentes em nosso país, em especial pela grade curricular do curso de formação de professores investigado? Como os futuros professores de inglês do curso investigado entendem o ensino de inglês na atualidade e o uso das novas tecnologias para o ensino e aprendizagem de inglês como língua internacional?
${ }^{1}$ Neste artigo, o termo "formação tecnológica" remete à formação docente necessária face ao advento das novas tecnologias e do letramento digital, e não ao ensino técnico.

${ }^{2} \mathrm{O}$ termo língua internacional refere-se ao uso de uma determinada língua (materna ou adicional) no contexto internacional, tanto por nativos como por não nativos dessa língua. 
${ }^{3} \mathrm{O}$ termo ensinagem tem sido utilizado mais recentemente na área da educação na intenção de substituir os termos ensino e aprendizagem separadamente, não marcando assim sua dicotomia, mas sua íntima relação no que diz respeito não só a sua concepção, mas também em termos de práxis pedagógica (NICOLAIDES; TILIO, 2013, p.288).

${ }^{4}$ Seguindo sugestões de Nicolaides e Tílio (2013, p. 285) adotamos o termo língua adicional no lugar de língua estrangeira por entender que o termo língua adicional expressa melhor o que pensamos que deva ser o ensino de uma língua que não a materna. Entendemos o usuário da língua como alguém que, por opção ou exposição, aprende uma língua ou mais, além da sua materna, não denotando uma língua como inferior à outra, ou de valor simbólico diferente. $O$ termo língua estrangeira, ao contrário, parece sugerir que a língua seja estranha ou exótica, com conotações indesejáveis. Pensamos que o termo adicional represente nossa visão de que as línguas que não a materna, não são inferiores, superiores, ou mesmo substitutivas da primeira língua.

\section{Políticas Linguísticas}

O Brasil é um país multilíngue com dezenas de línguas minoritárias (LEFFA, 2013) que vive atualmente sob duas pressões externas oriundas do contexto globalizado mundial: a necessidade de aprender a língua dos vizinhos (espanhol) e a de aprender inglês como língua internacional, vencendo possíveis obstáculos ideológicos com relação à ensinagem ${ }^{3}$ dessa última língua como língua adicional (doravante LA). ${ }^{4}$

Vivemos na era da informação (LEVY, 1999) que circula, em sua maior parte, em inglês e através de cliques (FINARDI; PREBIANCA; MOMM, 2013) mas onde as práticaslocais deensinagem deinglês (por exemploFINARDI; PREBIANCA, no prelo) nem sempre refletem o status global desse idioma ou a necessidade do desenvolvimento do letramento digital como forma de expandir o acesso amplo à informação (WARSCHAUER, 2003).

Lagares (2013, p. 185) e Rajagopalan (2006) nos lembram que o ensino de línguas estrangeiras é, claramente, uma questão política, uma vez que os aspectos metodológicos que incidem diretamente na sala de aula decorrem de decisões tomadas alhures. A própria decisão sobre quais línguas estrangeiras incluir no currículo escolar é uma questão política.

Segundo Lagares (2013, p. 185), o ensino de línguas estrangeiras no Brasil foi por vezes tratado como componente extracurricular, passando até por um processo de terceirização onde a língua estrangeira tinha uma função instrumental, baseada na crença comum de que a escola não é lugar para aprender línguas estrangeiras (p. 186). Essa noção é questionada por autores (TILIO, no prelo, apud NICOLAIDES; TILIO, 2013, p. 294) que sugerem que assim como a escola não forma matemáticos, ela não deveria ter a responsabilidade de formar falantes fluentes de línguas estrangeiras. 
Gimenez (2009 apud MACIEL, 2013, p. 238) nos lembra de que há dois mundos paralelos: o dos documentos oficiais e o da sala de aula e nessa discussão, para Rajagopalan (2006), o ensino de línguas deve ater-se às demandas impostas pelas relações políticas nas quais se encontra o país (RAJAGOPALAN, 2006, p.22 apud LAGARES, 2013, p. 197).

Nesse sentido, acreditamos ser imprescindível uma reflexão sobre as possíveis implicações de ensinar (ou não) inglês como língua estrangeira ou internacional (levando em consideração o uso global da língua e não o contexto de aprendizagem) no atual contexto geopolítico brasileiro. A análise de políticas linguísticas feita aqui sugere que o inglês tem status de língua internacional no atual cenário global, porém tal status não é refletido nas práticas locais onde o inglês é ensinado no Brasil como língua estrangeira, podendo, inclusive, ser omitido do currículo obrigatório em favor de outro idioma estrangeiro, de acordo com os documentos legais.

Apesar de o desempenho dos brasileiros em inglês ocupar o 46o lugar em um ranking de 54 países, conforme relatado por Gimenez (2013, p. 202), parece haver um movimento rumo à conscientização sobre a importância do ensino de inglês no Brasil como demonstram políticas de internacionalização concretizadas nos Programas Ciência sem Fronteiras e Inglês sem Fronteiras. ${ }^{5}$

O que é aparentemente intrínseco a ambos os programas governamentais é que, independentemente de políticas linguísticas ou de sentimentos antagônicos no tocante à possível hegemonia do inglês em relação a outras línguas (veja LEFFA, 2006; 2013), parece haver um consenso de que os brasileiros querem e precisam aprender inglês, conforme atestam políticas de internacionalização ainda desconectadas de políticas linguísticas de ensino de língua estrangeira. Vale ressaltar que a ausência de políticas alinhadas ao desejo popular pode acarretar
${ }^{5} \mathrm{O}$ Programa Ciências sem Fronteiras é um programa de internacionalização e mobilidade acadêmica estudantil cuja baixa adesão às bolsas ofertadas para estudantes universitários brasileiros se deve, principalmente, à falta de proficiência no inglês dos candidatos à bolsa. A fim de suprir essa lacuna o governo lançou em 2012 o Programa Inglês sem Fronteiras cujo objetivo é capacitar estudantes universitários brasileiros para o uso do inglês academicamente. 
${ }^{6}$ Protestos iniciados em várias regiões do Brasil em junho de 2013 com o Movimento Passe Livre. sérias consequências sociais como temos presenciado nos vários protestos ocorridos em todo o país recentemente. ${ }^{6}$ No caso da ausência de políticas linguísticas para a internacionalização e para o ensino de inglês comolíngua internacional no Brasil, uma dessas consequências é a desigualdade de oferta de cursos de inglês, favorecendo o ensino no setor privado e aumentando assim a desigualdade social através da terceirização da oferta de cursos livres de inglês que efetivamente formem falantes fluentes e proficientes do idioma. Outra consequência é a indesejável dissociação dos dois papeis essenciais da língua inglesa, sendo visto ora como formador na educação pública e ora como instrumental no setor privado.

Neste ínterim, parece-nos importante não apenas ampliar o debate em torno de políticas linguísticas bem como em torno do reconhecimento da necessidade de haver mais investimento no profissionalismo docente, preparando professores de inglês para as devidas mediações entre linguagens, tecnologias e os contextos locais e globais (MONTE MÓR, 2013, p. 233).

Nesse sentido, Graddol (2006), Finardi, Prebianca e Momm (2013) e Warschauer (2003; 2006) sugerem que o inglês e a tecnologia ampliam o acesso à informação na era do conhecimento. Finardi, Prebianca e Momm (2013) sugerem ainda, que a ampliação do acesso à informação, por meio do letramento digital e do conhecimento de inglês pode levar à formação de capital social definida por Warschauer (2003) como a capacidade que os indivíduos têm de gerar benefícios mediante seus relacionamentos pessoais em estruturas e redes sociais. $\mathrm{O}$ autor distingue ainda dois tipos de acesso às tecnologias de informação e comunicação (TICs): o acesso restrito e o acesso amplo. Segundo Warschauer (2003), o acesso restrito se resume à pura e simples manipulação de equipamentos tecnológicos, o que não conduz necessariamente à formação de capital social. Para que haja formação de 
capital social através do uso das TICs, Warschauer (2003) sugere que deve haver um acesso amplo que pressupõe o uso crítico das tecnologias disponíveis a favor da educação e dos indivíduos.

\section{Políticas Linguísticas de Ensino de Língua Estrangeira}

A Resolução CNE/CEB 7/2010 estabelece que a língua estrangeira moderna é componente curricular obrigatório. A mesma resolução, bem como a Lei de Diretrizes e Bases da Educação (LDB), prevê que seja ofertado, obrigatoriamente, a partir do 6o. ano o ensino, pelo menos uma língua estrangeira moderna, cuja escolha ficará a cargo da comunidade escolar. A Resolução CNE/CEB 7/2010 prevê ainda que, entre as línguas estrangeiras modernas, a língua espanhola poderá ser uma opção, demonstrando expressamente a preferência por esse idioma.

Independentemente da justificativa para a escolha do espanhol na Resolução CNE/CEB 7/2010, fica patente a ambiguidade subjacente nas políticas linguísticas no Brasil que ora veem o ensino de língua estrangeira como componente do núcleo de formação básica, ora como integrante da parte diversificada do currículo; ora ofertada de acordo com a escolha da comunidade escolar; ora sendo a língua espanhola; ora sendo a língua inglesa. Entretanto, e como ainda nos lembra Gimenez (2013, p. 208), "correndo por fora" e fortalecida pela globalização econômica, está a língua inglesa, cujo caráter distintivo em relação às demais línguas se torna visível na política de internacionalização que o Brasil adota, um pouco tardia e desorganizadamente por não se articular com políticas educacionais e linguísticas de base, como fica claro no tratamento dado ao inglês e a outras línguas estrangeiras na LDB e na Resolução CNE/CEB 7/2010. 
As políticas linguísticas vigentes em nosso país parecem ainda mais conflitantes em face do progresso tecnológico que passou a exigir diferentes leituras de mundo e habilidades dos indivíduos no século XXI. Desta forma, novos letramentos surgiram a partir da percepção de que as mudanças sociais, culturais e políticas advindas dos conhecimentos da tecnologia digital e do fenômeno da globalização exigiam um novo olhar sobre premissas educacionais até então praticadas, reconhecendo o papel das tecnologias e das linguagens nas mediações entre os contextos local e global (MONTE MÓR, 2013, p. 230).

Não obstante, as políticas educacionais para o uso das novas tecnologias tem sido um dos focos do governo federal brasileiro, de acordo com o Plano Nacional da Educação elaborado em 2001 em prol da formação para uso das tecnologias e a consequente melhora do ensino presencial (PAIVA, 2013). Os programas governamentais para a formação tecnológica do professor - o ProInfo e o ProInfo Integrado -, têm como objetivos a distribuição e montagem de laboratórios de informática em escolas de ensino fundamental e médio, e a capacitação de professores e gestores educacionais para o uso das novas tecnologias em suas práticas pedagógicas (PAIVA, 2013). Ambos visam ainda, conforme alega Paiva (2013), preparar os alunos para viver no mundo globalizado do século XXI, que exige novas habilidades tais como o pensamento crítico, o letramento digital, a capacidade de integrar diferentes mídias e tecnologias, entre outras.

Apontamos assim a necessidade de políticas linguísticas e de formação docente para uso das novas tecnologias que deem conta de um ensino de línguas plural, em consonância com os anseios dos indivíduos que as usam, que as modificam e se apropriam delas e que escolhem quando, onde e com quem querem se comunicar e talvez o mais importante, como o farão (eis que surgem as novas tecnologias!). 
Uma tentativa de preparar os alunos para o mundo globalizado pode ser vista nas Orientações Curriculares para o Ensino Médio, Línguas Estrangeiras - OCEMLEM, que reafirmam a noção de cidadania dentro da prática de línguas estrangeiras através da revisão do papel da linguagem e da inclusão de novas tecnologias para as mediações nos contextos local e global (MONTE MÓR, 2013; BRASIL, 2006, p.87).

Em outras palavras, as OCEM-LEM representam uma visão de ensino de inglês como parte de um letramento crítico entendido como a capacidade de educar indivíduos para recriar suas identidades e realidades sociopolíticas por intermédio de processos de reflexão e re-significação de suas ações no seu entorno, incluindo o reconhecimento do papel que o inglês e a tecnologia têm como linguagens de acesso à informação e inclusão social no mundo globalizado (FINARDI; PREBIANCA; MOMM, 2013). Entretanto, esse papel nem sempre é reconhecido conforme atestam estudos sobre o ensino de inglês no Brasil (por exemplo FINARDI; PREBIANCA, no prelo) e sobre a inclusão de tecnologias de informação e comunicação (TICs) no ensino presencial (TEIXEIRA; FINARDI, 2013; FINARDI et al., 2014).

Ainda sobre as contradições e lacunas observadas nas políticas linguísticas de ensino de línguas estrangeiras no Brasil observamos que nos Parâmetros Curriculares Nacionais - PCN- (BRASIL, 1998) o foco do ensino de língua estrangeira é a leitura. Tal foco é contrário às sugestões das OCEM-LEM (BRASIL, 2006) uma vez que estas valorizam a integração das habilidades de leitura, compreensão oral e prática escrita, enfatizando ainda a importância de se trabalhar outras habilidades como o letramento crítico, o letramento digital ${ }^{7}$ e a oralidade.

Semelhantemente às resoluções e orientações que compõe os documentos oficiais que regem o ensino de línguas estrangeiras na educação básica brasileira,
${ }^{7}$ Podemos entender o letramento digital como sendo a capacidade de navegar na internet, avaliar e criar informação e conteúdos de maneira eficiente e crítica usando tecnologias digitais. 
${ }^{8}$ Artigo 23 e 26

da Declaração

Universal dos Direitos

Linguísticos. outro tipo de política de ensino de língua estrangeira na qual identificamos lacunas e contradições é a política, ainda um pouco incipiente, de internacionalização do ensino superior (NICOLAIDES; TILIO, 2013). Dentre os desafios a serem vencidos rumo à internacionalização do ensino superior, Nicolaides e Tilio (2013, p. 296), Finardi e Ortiz (2014) e Finardi e França (no prelo) citam a barreira linguística (leia-se: falta de proficiência na língua inglesa para permitir maior mobilidade acadêmica e circulação de produção científica internacional) como sendo o maior deles.

Sabemos que a educação linguística é um direito $^{8}$ de aprendizagem que tem sido realizado de modo insuficiente no Brasil no tocante ao inglês. Com o objetivo de reunir ações voltadas para sanar essa lacuna, o MEC lançou em 18 de dezembro de 2012 o Programa Inglês Sem Fronteiras, que tem como objetivo melhorar a proficiência em inglês de estudantes universitários brasileiros. Ainda que relevante, tal iniciativa parece não incorporar a necessidade do ensino de inglês a todos os níveis da educação por meio de políticas linguísticas que reflitam essa realidade. Neste sentido, o presente artigo reflete sobre o papel da formação de professores de inglês para o século XXI levando em consideração todas as questões aqui levantadas.

Entendemos que a política de internacionalização concretizada em ações como o Programa Ciência sem Fronteiras é limitada e paradoxal, uma vez que pressupõe que o país precisa de profissionais de tecnologia e ciências exatas qualificados internacionalmente (NICOLAIDES; TILIO, 2013, p. 298) ao mesmo tempo em que exclui do programa a área de Letras, responsável, a priori, pela formação dos profissionais capazes de preparar aqueles outros para a vivência no exterior. Entretanto, programas como o Inglês sem Fronteiras podem representar uma tentativa de corrigir tal paradoxo, contribuindo para o 
desenvolvimento de uma melhor proficiência em inglês e do letramento internacional ${ }^{9}$ se vierem aliados às políticas linguísticas e de incentivo à formação docente para o atual cenário mundial; políticas essas que devem permear todas as esferas educacionais brasileiras de forma homogênea e coerente. Eis a provocação que este estudo pretende fazer. A fim de subsidiar a reflexão proposta, o presente estudo analisa aspectos pontuais de um curso de formação de professores de inglês de uma universidade federal do sudeste. A próxima seção descreve a metodologia utilizada para tanto.

\section{Metodologia}

A fim de refletir sobre o papel do inglês no Brasil contemporâneo tendo em vista as políticas linguísticas e a formação tecnológica dos futuros professores de inglês, o presente estudo analisou qualitativamente (DORNYEI, 2007) as ementas das disciplinas de Estágio Supervisionado I e Estágio Supervisionado II, as notas de observações das aulas teóricas e práticas dessas disciplinas ao longo de um semestre letivo e a grade curricular do curso de Licenciatura em Letras Inglês de uma universidade federal do sudeste brasileiro. A perspectiva da análise qualitativa adotada é de uma pesquisa que busca compreender o comportamento humano e as razões que o governam por meio de perguntas como por que e como em relação à tomada de decisão dos envolvidos (DORNYEI, 2007).

\section{As disciplinas de Estágio Supervisionado I e Estágio Supervisionado II}

O estágio supervisionado do curso de Licenciatura em Letras Inglês da universidade federal investigada é uma disciplina dividida em dois módulos. O primeiro módulo Estágio supervisionado I - é ofertado no sétimo período do
${ }^{9}$ Entendemos que o letramento internacional se refere ao letramento crítico e uso de línguas e linguagens de forma crítica no contexto internacional. 
curso e corresponde à prática no ensino fundamental. $\mathrm{O}$ segundo módulo - o Estágio supervisionado II - é ofertado no oitavo período do curso e corresponde à prática no ensino médio. A carga horária de cada módulo (200 horas) é distribuída entre 80 horas de aulas presenciais (conteúdo teórico) e 120 horas de prática de ensino (conteúdo prático) nas escolas públicas sob a supervisão do professor regente (professor da turma) e do professor supervisor (professor da disciplina de estágio).

As ementas das disciplinas de estágio supervisionado I e estágio supervisionado II preveem a observação, vivência e análise crítica dos processos educativos e didático-pedagógicos que ocorrem na escola. As ementas consideram também a dimensão dos processos de ensino-aprendizagem e as relações teóricopráticas no cotidiano escolar discutindo o conceito de currículo, o planejamento, as ações pedagógicas, a seleção e organização de conteúdos, metodologias de ensino, o material didático e a análise crítica de seus textos, o exame de seus conteúdos, a avaliação da aprendizagem e as ações docentes, entendidas como regência de classe, contemplando a elaboração e a operacionalização de projetos pedagógicos, com orientação para o ensino fundamental no caso da disciplina de Estágio Supervisionado I e para o ensino médio no caso da disciplina de Estágio Supervisionado II.

Os objetivos das disciplinas são: 1) Estabelecer contato inicial com a realidade do campo de atuação, articulando os conhecimentos específicos adquiridos com a prática; 2) Problematizar a prática docente, desenvolvendo pesquisa e propondo ações de intervenção; 3) Avaliar permanentemente a prática, estabelecendo uma visão crítica de reflexão e questionamento no estágio, com o intuito de aprimorar e amadurecer os conhecimentos obtidos durante sua formação acadêmica e a prática pedagógica desenvolvida e vivenciada; 4) Despertar para o 
desenvolvimento dos princípios do exercício profissional, com responsabilidade e ética profissional e pessoal; 5) Perceber a ligação entre o conhecimento específico a que se propõe ensinar e os demais campos do conhecimento humano; 6) Propiciar ao aluno a vivência de atividades e dos problemas do dia-a-dia inerentes à função docente.

O conteúdo programático das disciplinas de estágio, por sua vez, compreende as bases conceituais sobre a prática e os saberes docentes; as bases conceituais sobre trabalho docente, escola e currículo; as bases conceituais sobre interdisciplinaridade e avaliação de aprendizagem; aspectos históricos e legais do processo de ensino e aprendizagem da língua inglesa no Brasil e conceitos básicos sobre a questão do professor reflexivo.

A metodologia de ensino dessas disciplinas em termos gerais compreende aulas expositivas e dialogadas, encontros individuais e em grupos para planejamento e reflexão, atividades em campo de estágio com planejamento, elaboração e avaliação de material didático e a produção do relatório do estágio. O critério de avaliação nessas disciplinas é contínuo e engloba a participação oral em sala com a leitura, discussão e apresentação dos textos do programa e a produção de e reflexão sobre o relatório do estágio.

A prática do estágio consiste na aproximação (observação das aulas) da escola e da turma onde a equipe realizará o estágio, sendo seguida pela fase de assessoramento, na qual além de observar o professor regente, responsável pela turma na escola onde a prática ocorre, os estagiários auxiliam em tarefas como fazer a chamada, responder dúvidas de alunos durante atividades individuais e monitorar a turma. A última fase da prática é a de regência de aula que é supervisionada pelo professor regente e pelo professor supervisor da disciplina de estágio. 
${ }^{10} \mathrm{~A}$ fim de respeitar o número máximo de páginas estipulado, não podemos nos aprofundar nas diferentes concepções do inglês no presente artigo. Para tanto, sugerimos a leitura de Jordão (2014) para uma revisão desses termos associados à língua inglesa.
A análise dos objetivos, ementa, metodologia e prática das disciplinas de Estágio Supervisionado I e do Estágio Supervisionado II não mostra de forma clara e explícita como a formação do professor de inglês para as devidas mediações da língua e da tecnologia se dão nesse curso. Parece-nos que essa formação fica a critério da interpretação do professor supervisor dessa disciplina.

\section{Percepções dos futuros professores de inglês durante as aulas das disciplinas de Estágio Supervisionado I e Estágio Supervisionado II}

Durante as discussões realizadas nas aulas das disciplinas de Estágio Supervisionado I e Estágio Supervisionado II ao longo do segundo semestre de 2012, foram feitas anotações das observações pelo professor supervisor-pesquisador. Alguns temas relevantes para a reflexão proposta neste estudo foram levantados nessas discussões e anotados durante as observações das aulas e serão analisadas no que segue.

O primeiro refere-se ao papel do inglês no mundo contemporâneo e surgiu a partir de um questionamento provocado pelo professor supervisor sobre as diferentes terminologias associadas ao inglês: Língua Internacional (MCKAY, 2002); Língua Franca (JENKINS, 2006; SEIDLHOFER, 2001; El KADRI; GIMENEZ, 2013); World English (RAJAGOPALAN, 2010); Língua Global (por exemplo, GRADDOL, 2006) e Língua Internacional de Inclusão Social (por exemplo, FINARDI, PREBIANCA; MOMM, 2013). ${ }^{10}$

No bojo da discussão, chegou-se à conclusão de que no ensino público brasileiro, o inglês tem status de língua estrangeira já que é ensinado como o espanhol ou outra língua estrangeira qualquer, em geral com carga horária de duas aulas por semana. Segundo a percepção 
dos alunos-futuros professores de inglês, nas escolas privadas o inglês é ensinado como língua internacional uma vez que a língua estrangeira ofertada nesse contexto em geral é o inglês e a carga horária em geral é maior do que nas escolas públicas, sendo que cursos de inglês extracurriculares são ainda disponibilizados pelas escolas privadas em parceria com institutos de idiomas.

A partir dessa discussão, o professor supervisor propôs uma reflexão sobre o status do inglês nas escolas públicas no Brasil diante de estatísticas (GRADDOL, 2006) que mostram que esse idioma tem hoje status de língua internacional ou língua franca (GIMENEZ, 2013), ou seja, o inglês é o idioma mais falado do mundo tanto por nativos quanto por não nativos desse idioma. Em face da necessidade de dominar o inglês para exercer a cidadania plena no mundo globalizado (ver FINARDI, PREBIANCA; MOMM, 2013), foi proposto pelo professor supervisor que o ensino de inglês (como língua internacional e não como língua estrangeira) deveria ser obrigatório e ter carga horária maior que a do ensino de língua estrangeira que poderia continuar no currículo sem nenhum prejuízo já que a função de uma língua estrangeira não é a mesma da língua internacional. Segundo a visão do professor supervisor, uma língua estrangeira tem uma função mais formadora enquanto a língua internacional, além desse papel, tem um papel instrumental. Outra distinção originada na discussão sobre o papel do inglês se refere ao contexto onde ele é usado: uma língua estrangeira não é usada no país onde ela é aprendida enquanto uma língua internacional é.

Decorrente da sugestão de aumentar a carga horária do ensino de inglês nas escolas públicas, outra questão, de ordem metodológica, foi levantada pelos futuros docentes: como alcançar essa promoção do status do inglês frente à política linguística vigente? Sabemos que a LDB prevê que uma (nosso grifo) língua estrangeira (não necessariamente o inglês), seja ensinada a partir do 6ㅇ. 
ano. Apesar de a maior parte das escolas públicas oferecer aulas de inglês, a carga horária designada para esse idioma em geral é de duas aulas de 50 minutos por semana, ou seja, uma carga horária que parece mais apropriada para o ensino de língua estrangeira do que para o de uma língua internacional que é mais usada do que qualquer língua estrangeira, como sugerido anteriormente. $\mathrm{Na}$ esteira das discussões sobre metodologia de ensino de inglês e sobre o status desse idioma, surgiu, entre os futuros docentes, uma discussão sobre o problema da falta de carga horária para o ensino de inglês como língua internacional. O professor supervisor sugeriu então o uso de uma metodologia de ensino de línguas por meio de conteúdos diversos, conhecida como Content and Language Integrated Learning (CLIL) em inglês. De acordo com essa metodologia, o professor ensina conteúdos diversos na língua alvo. Através dessa metodologia é possível aumentar o tempo de exposição do aluno ao idioma alvo (através da parceria com outros professores de outras disciplinas), ajudando-o a pensar em conteúdos diversos (e relevantes) em inglês, maximizando assim o aprendizado tanto do conteúdo quanto do meio, neste caso, a língua. Essa metodologia é vista por alguns autores como sendo uma metodologia de ensino crítico (por exemplo, FINARDI, no prelo) e parece propiciar também o desenvolvimento do letramento crítico na medida em que prepara alunos para as mediações da língua não apenas dentro, mas também fora da escola, onde novas habilidades e diferentes padrões de raciocínio são exigidos do aluno. Essa metodologia foi discutida durante as aulas presenciais do estágio supervisionado de inglês como uma forma de minimizar o impacto de uma reduzida carga horária dedicada ao ensino de inglês nas escolas públicas já que por meio dessa metodologia é possível ampliar o contato dos alunos com a língua alvo por meio da parceria com professores de outras disciplinas. 
Outro tema discutido nas aulas do estágio supervisionado de inglês foi o papel da tecnologia na era da informação e no mundo globalizado no qual vivemos. Nesse sentido, o professor supervisor do estágio supervisionado propôs que fossem incorporadas algumas possibilidades da web 2.0 para o ensino de inglês (FINARDI; PREBIANCA; MOMM, 2013) nos planos de aula elaborados pelos estagiários, usando abordagens híbridas que conjugam a instrução presencial com a instrução mediada por tecnologias digitais (FINARDI, 2012) a fim de desenvolver o letramento digital além da proficiência em inglês.

A sugestão foi acatada pelos estagiários que produziram planos de aula usando quatro possibilidades da web 2.0, uma para cada habilidade trabalhada. Para desenvolver a habilidade de compreensão e produção oral foram propostas diversas atividades usando podcasts para a compreensão oral e o voicethread, ferramenta da web que permite a interação assíncrona via oral, para desenvolver a habilidade da fala em inglês. Para desenvolver a habilidade de leitura e escrita de forma integrada foram propostas atividades usando duas ferramentas da $w e b$, a wikipédia e o webquest. A inclusão dessas ferramentas tecnológicas teve um impacto positivo tanto no professor regente quanto nos alunos que as experimentaram durante as aulas de inglês, conforme observado durante a regência desses planos de aula nas escolas regulares onde os alunos estagiavam, e os relatos de alunos nas sessões de reflexão sobre o estágio supervisionado durante as aulas da disciplina de estágio supervisionado.

\section{A grade curricular do curso de Letras Inglês}

A motivação para análise da grade curricular do curso de Licenciatura em Letras Inglês de uma universidade 
federal reside na importância da prática refletir o que a teoria proposta pelas políticas linguísticas prega no que se refere ao ensino de inglês em nosso país. Como discutido em seções anteriores, a falta de clareza e direcionamento das políticas linguísticas para conduzir a um ensino crítico de inglês que contribua para formação de capital social dos indivíduos que o utilizam para se comunicar, não diz respeito apenas a leis, resoluções ou pareceres. De nada vale uma política voltada para as necessidades de um mundo globalizado e altamente tecnológico, se a formação docente, em especial das universidades federais, que bebem (ou pelo menos deveriam beber) da mesma água do Estado, não é coerente com as ações governamentais.

Uma maneira de estabelecer uma ligação entre teoria e prática, nesse caso, é garantir que as universidades ofertem, em seus cursos de licenciatura, uma grade curricular coerente com as necessidades de uma educação para o futuro afinada aos contextos global e local. Admitimos, no entanto, que a simples oferta de uma grade curricular em sincronia com as necessidades sociais não é suficiente para assegurar bons resultados, porém conjuga-se como uma forma de garantir que a inclusão de temas atuais e relevantes como a tecnologia, por exemplo, não fique a cargo da interpretação do professor. Outro fator importante para garantir uma boa educação para o século XXI é um maior investimento na carreira docente, tanto na educação inicial quanto na continuada, a fim de fomentar as devidas apropriações e mediações entre língua e tecnologia.

Nesse sentido, o presente estudo analisou a grade curricular do curso de licenciatura em Letras Inglês de uma universidade federal (UF), com base em três dimensões do modelo de formação tecnológica do professor proposto por Paiva (2013). Neste modelo, Paiva (2013) defende que a formação docente para uso da tecnologia deve acontecer de forma institucionalizada e não por meio de ações 
individuais e não sistematizadas. Daí nossa sugestão de que a inclusão de temas como a tecnologia não fique a critério da interpretação do professor formador, mas conste na grade curricular dos cursos de formação docente.

Segundo Paiva (2013), professores formadores devem ser modelo para professores em formação, incorporando o uso de novas tecnologias à suas práticas pedagógicas de forma crítica e deliberada em suas aulas nos cursos de licenciatura. Infelizmente, Teixeira e Finardi (2013) nos mostram que o uso de TICs no ensino presencial por professores formadores é ainda muito tímido e Finardi et al. (2014) reportam que há uma lacuna entre crenças de professores e alunos sobre o uso das TICs na educação no Brasil. Os professores parecem resistir à incorporação das TICs na educação por razões que vão desde o peso extra representado por sua constituição até a percepção da necessidade de um maior investimento na formação docente para a utilização das TICs. Já os alunos parecem ter uma clara preferência por abordagens híbridas que combinam o uso das TICs às aulas tradicionais. Finardi et al. (2014) concluem que os resultados desse estudo podem ser tomados como evidência de que enquanto práticas pedagógicas não estiverem alinhadas às demandas da sociedade, os professores podem continuar a perceber um baixo nível de motivação e envolvimento por parte dos alunos.

Para Paiva (2013), três critérios precisam ser atendidos na dimensão Ensino para fomentar a formação tecnológica docente: (1) a inserção das novas tecnologias na prática pedagógica de professores formadores; (2) a inserção, no currículo do curso, de disciplinas específicas sobre novas ferramentas e gêneros digitais, e (3) a utilização das tecnologias em ações de estágio no ensino básico. No que segue, apresentamos a análise da grade curricular do curso Letras Inglês (Apêndice 1) da UF investigada com base nesses critérios. 
Em relação ao critério da inserção das novas tecnologias na prática pedagógica de professores formadores não podemos afirmar, com base na grade curricular do curso de Letras Inglês (Anexo 1), que essa prática ocorra porém, como mencionado aqui, Teixeira e Finardi (2013) e Finardi et al. (2014) concluíram que esse uso é muito aquém do esperado de professores formadores no século XXI.

O segundo critério alencado por Paiva (2013) diz respeito à inclusão de disciplinas específicas sobre o letramento digital e novos gêneros no currículo. Ainda que nenhuma disciplina tenha sido encontrada com essa especificidade na grade curricular investigada (Apêndice 1), vale notar que nas disciplinas de Tópicos e Projetos de Ensino de Língua Inglesa, ofertadas entre os $1^{\text {os. }}$ e 6 os. períodos, esses conteúdos são geralmente propostos, porém de forma individual e não institucionalizada já que cabe ao professor propor esses conteúdos nos programas dessas disciplinas.

Finalmente, o terceiro critério que elencamos, o da utilização das tecnologias em ações de estágio no ensino básico, parece ter fundamento nas observações das disciplinas e práticas de estágio supervisionado na instituição investigada, conforme relatado anteriormente na observação dos planos de aula elaborados. Entretanto, cabe-nos ressaltar que o currículo do curso em si não garante, por si só, a formação docente para o século XXI, uma vez que esta parece ficar a mercê da interpretação, formulação do programa a cabo de cada professor.

\section{Conclusão}

Este estudo teve como objetivo refletir sobre o ensino e aprendizagem de inglês no Brasil contemporâneo. Para tanto o estudo revisou políticas linguísticas de ensino de línguas estrangeiras e analisou a prática das disciplinas 
de estágio supervisionado de inglês e a grade curricular de um curso de licenciatura em Letras Inglês de uma universidade federal. Resultados da análise sugerem que é necessário ampliar a formação docente para o uso da tecnologia através da inclusão dessa nas três dimensões propostas por Paiva (2013): na prática docente; no currículo dos cursos de formação e no estágio da educação básica. A análise apontou ainda uma lacuna entre a política linguística de ensino de línguas estrangeiras e a prática do ensino de inglês como língua internacional no Brasil sugerindo que as políticas de internacionalização devem ser pensadas e propostas em conjunto com as políticas de ensino de língua estrangeira. 


\section{Referências}

BRASIL. MEC/SEB. Orientações curriculares para o ensino médio. Brasília: MEC, 2006.

BRASIL. MEC/SEF. Parâmetros Curriculares Nacionais Língua Estrangeira - 3o e 4 Ciclos do Ensino Fundamental. Brasília: MEC, 1998.

DORNYEI, Z. Research methods in applied linguistics: quantitative, qualitative and mixed methodologies. Oxford: Oxford University Press, 2007.

EL KADRI, M.; GIMENEZ, T. Formando professores de inglês para o contexto do inglês como língua franca. Acta Scientiarum. Language and Culture. Maringá, v. 35, n. 2, p. 125-133, Apr.-June, 2013.

FINARDI, K. Refletindo sobre abordagens críticas de ensino de língua estrangeira. Em: LYRIO, A.L.L. (Org) Linguística aplicada: ensino, pesquisa e reflexões. Vitória, ES: Pontes/ EDUFES, 2014, no prelo.

FINARDI, K. Technology and L2 learning: hybridizing the curriculum. In: Language and Literature in the Age of Technology - Anais do III Congresso Internacional da ABRAPUI. Universidade Federal de Santa Catarina. BECK, M. S.; SILVEIRA, R.; FUNCK, S. B.; XAVIER, R. P. (Organizadoras). Florianópolis: Universidade Federal de Santa Catarina, 2012. v. 1. p. 1-8.

FINARDI, K. R. ; PREBIANCA, G. ; MOMM, C. F. Tecnologia na Educação: o caso da Internet e do Inglês como Linguagens de Inclusão. Cadernos do IL, v. 46, p. 193-208, 2013.

FINARDI, K.; DALVI, M. A. Encurtando as distâncias entre teoria-prática e universidade-escola no ensino de línguas e na formação de professores. Intersecções (Jundiaí), v. 5, p. 115127, 2012. 
FINARDI, K. R.; FRANÇA, C. O inglês na internacionalização da produção científica brasileira. Artigo submetido à Revista Educação \& Realidade em maio de 2014.

FINARDI, K. \& ORTIZ, R. A. Globalization, Internationalization and Education: What is the connection?. In: INTCESS14- International Conference on Education and Social Sciences, 2014, Istambul. Proceedings of INTCESS14International Conference on Education and Social Sciences. Istambul: Ocerint. v. 1. p. 45-53. 2014.

FINARDI, K. ; PREBIANCA, G. Ensino Crítico de Inglês e Formação Docente na Contemporaneidade. Artigo submetido à Revista Eletrónica de Enseñanza de las Ciencias. - REEC. 2014. No prelo.

FINARDI, K.; TEIXEIRA, D.; PREBIANCA, G.; DOS SANTOS JÚNIOR, V. P. Information Technology and Communication in Education: Two Sides of the Coin in Brazil. International Journal of Recent Contributions from Engineering, Science \& IT (iJES), v. 2, p. 21-25, 2014.

FREEMAN, D; RICHARDS, J. (Ed.). Teacher Learning in Language Teaching. Cambridge: Cambridge University Press, 400p, 1996.

GIMENEZ, T. A ausência de políticas para o ensino da língua inglesa nos anos inciais de escolarização no Brasil. In: NICOLAIDES, C.; SILVA, K.A.;TÍLIO, R.; ROCHA, C.H. (Orgs.) Política e Políticas Linguísticas. Campinas: Pontes Editores, 2013. p.199-218.

GRADDOL, D. English Next: why global English may mean the end of "English as a foreign language". The English Company (UK) Ltd. British Council. pp.132. 2006. Disponível em $<$ http://www.britishcouncil.org/learning-research-englishnext.pdf $>$.

JENKINS, J. Current perspectives on teaching world Englishes and English as a lingua franca. TESOL Quarterly, v. 40, n. 1, p. 157-181, 2006. 
JOHNSON, K.; FREEMAN, D. Teacher learning in second language teacher education: a socially situated perspective. Revista Brasileira de Linguística Aplicada, v.l, n.1,53-69, 2001.

JORDÃO, C. M. ILA - ILF- ILE - ILG: Quem dá conta? Revista Brasileira de Linguística Aplicada, v. 14, p. 13-40. 2014.

LAGARES, X. C. Ensino do espanhol no Brasil: uma (complexa) questão de política linguística. In: NICOLAIDES, C.; SILVA, K.A.;TÍLIO, R.; ROCHA, C.H. (Orgs.) Política e Políticas Linguísticas. Campinas: Pontes Editores, 2013, p.181198.

LEFFA, V. Prefácio. In: NICOLAIDES, C.; SILVA, K.A.;TÍLIO, R.; ROCHA, C.H. (Orgs.) Política e Políticas Linguísticas. Campinas: Pontes Editores, 2013, p.7-10.

LEFFA, V. J. Língua estrangeira hegemônica e solidariedade internacional. In: KARWOSKI, Acir Mário; BONI, Valéria de Fátima Carvalho Vaz (Orgs.). Tendências contemporâneas no ensino de inglês. União da Vitória, PR: Kaygangue, 2006, p. $10-25$.

LÉVY, P. Cibercultura. Editora 34. 264 p., 1999.

MACIEL, R. F. Políticas linguísticas, conhecimento local e formação de professores de línguas. In: NICOLAIDES, C.; SILVA, K. A.; TÍLIO, R.; ROCHA, C.H. (Orgs.) Política e Políticas Linguísticas. Campinas: Pontes Editores, 2013, p.237262.

MATEUS, E. Torres de babel e línguas de fogo: um pouco sobre a pesquisa na formação de professores de inglês. Revista Brasileira de Linguística Aplicada, v. 9, n.1, p.307-328, 2009.

MONTE MÓR, W. As políticas de ensino de línguas e o projeto de letramentos. In: NICOLAIDES, C.; SILVA, K.A.;TÍLIO, R.; ROCHA, C.H. (Orgs.) Política e Politicas Linguísticas. Campinas: Pontes Editores, 2013, p.219-236. 
NICOLAIDES, C. S.; TILIO, R.C. Políticas de ensino e aprendizagem de línguas adicionais no contexto brasileiro: o caminho trilhado pela ALAB. In: NICOLAIDES, C.; SILVA, K. A.; TÍLIO, R.; ROCHA, C.H. (Orgs.) Política e Politicas Linguísticas. Campinas: Pontes Editores, 2013. p.285-306.

MCKAY, S. L. Teaching English as an international language: rethinking goals and approaches. Oxford: Oxford University Press, 2002.

PAIVA, V. L. M . O. A formação do professor para uso da tecnologia. In: SILVA, K.. A.; DANIEL, F. G.; KANEKOMARQUES, S. M.; SALOMÃO, A. C. B. (Orgs) $A$ formação de professores de línguas: novos olhares. v. 2. Campinas, SP: Pontes Editores, 2013. p. 209-230.

RAJAGOPALAN, K. O ensino de línguas estrangeiras como uma questão política. In: MOTA, K; SCHEYERL, D. (Orgs.). Espaços Linguísticos: resistências e expansões. Salvador, EDUFBA, 2006. p.15-24.

RAJAGOPALAN, $\mathrm{K}$. The rigmarole of intelligibility in world English(es ) - or, on making sense of it all or, if you like, making the very idea of intelligibility intelligible. $R$. Let. \& Let. Uberlândia-MG, v.26, n.2, p. 477-492, jul/dez. 2010.

SEIDLHOFER, B. Closing a conceptual gap: the case for a description of English as a lingua franca. International Journal of Applied Linguistics, v. 11, n. 2, p. 133-158, 2001.

TEXEIRA, D.; FINARDI, K. TICs no ensino presencial: evidências de um curso de formação continuada na Universidade Federal do Espírito Santo. Contextos Linguísticos, v. 7, p. 79-96, 2013.

WARSCHAUER, M. Social capital and access. Universal Access in the Information Society, 2, (4). 2003.

WARSCHAUER, M. Tecnologia e inclusão social: a exclusão digital em debate. São Paulo: SENAC, 2006, 319 p.

Recebido em 06/01/2014

Aceito para publicação em 28/07/2014 
Apêndice 1 - Grade curricular de Letras Inglês, com o número de semestres letivos, a divisão das disciplinas por semestre e a carga horária de cada disciplina. ${ }^{11}$

\begin{tabular}{|c|c|c|}
\hline Disciplinas da grade curricular & \begin{tabular}{|l|} 
Semestre de oferta \\
\end{tabular} & Carga horária \\
\hline Língua Inglesa: Morfossintaxe & \begin{tabular}{|c|c}
1 &
\end{tabular} & 60 \\
\hline Língua Inglesa: Fonética e Fonologia & 1 & 60 \\
\hline Projeto de Ensino de Língua Inglesa I & 1 & 45 \\
\hline Tópicos de Ensino de Língua Inglesa I & 1 & 30 \\
\hline Latim I & 1 & 60 \\
\hline Introdução ao Estudos da Linguagem & 1 & 60 \\
\hline Psicologia da Educação: Desenvolvimento & 1 & 60 \\
\hline Língua Inglesa:Estudos Sintáticos & 2 & 60 \\
\hline Língua Inglesa: Prosódia & 2 & 60 \\
\hline Projeto de Ensino de Língua Inglesa II & 2 & 45 \\
\hline Tópicos de Ensino de Língua Inglesa II & 2 & 30 \\
\hline Variação Linguística & 2 & 60 \\
\hline Estudos Literários I & 2 & 60 \\
\hline Psicologia da Educação & 2 & 60 \\
\hline Língua Inglesa: Processo Cognitivo da Leitura & 3 & 60 \\
\hline Língua Inglesa: Comunicação Escrita e os Gêneros Textuais & 3 & 60 \\
\hline Língua Inglesa: Semântica & 3 & 60 \\
\hline Projeto de Ensino em Língua Inglesa III & 3 & 45 \\
\hline Tópicos de Ensino de Língua Inglesa III & 3 & 30 \\
\hline Estudos Literários II & 3 & 60 \\
\hline Introdução à Filosofia & 3 & 60 \\
\hline Língua Inglesa: Estudos Britânicos & 4 & 60 \\
\hline Língua Inglesa: Comunicação Oral & 4 & 60 \\
\hline Língua Inglesa: Comunicação Escrita e o Texto Acadêmico & 4 & 60 \\
\hline Língua Inglesa: Comunicação Através da Leitura & 4 & 60 \\
\hline Projeto de Ensino em Língua Inglesa IV & 4 & 45 \\
\hline Tópicos de Ensino em Língua Inglesa IV & 4 & 30 \\
\hline Política e Organização da Educação Básica & 4 & 60 \\
\hline Literatura Britânica: das Origens à Era Elizabetana & 5 & 60 \\
\hline Língua Inglesa: Estudos Americanos & 5 & 60 \\
\hline Língua Inglesa: Tradução - História Teórica e Prática & 5 & 60 \\
\hline $\begin{array}{l}\text { Linguística Aplicada ao Ensino de Língua Estrangeira: Processo de Aquisição } \\
\text { e Aprendizagem }\end{array}$ & 5 & 60 \\
\hline Projeto de Ensino em Língua Inglesa V & 5 & 45 \\
\hline Tópicos de Ensino de Língua Inglesa V & 5 & 30 \\
\hline Literatura Brasileira I: Periodização & 5 & 60 \\
\hline Literatura Britânica: Século XVII à Era Vitoriana & 6 & 60 \\
\hline Literatura Norte-Americana: Período Colonial Real. & 6 & 60 \\
\hline Língua Inglesa Tradução: Teorias e Práticas Atuais & 6 & 60 \\
\hline Linguística Aplicada Ensino Língua Estrangeira Processos Interacionais & 6 & 60 \\
\hline Projeto de Ensino em Língua Inglesa VI & 6 & 30 \\
\hline Tópicos de Ensino de Língua Inglesa VI & 6 & 30 \\
\hline Didática & 6 & 75 \\
\hline Estágio Supervisionado I & 7 & 200 \\
\hline Literatura Britânica Moderna e Contemporânea & 7 & 60 \\
\hline Literatura Norte-Americana Moderna e Contemporânea & 7 & 60 \\
\hline Currículo e Formação Docente & 7 & 60 \\
\hline Fundamentos Histórico-Filosóficos da Educação & 7 & 60 \\
\hline Trabalho de Conclusão de Curso & 8 & 60 \\
\hline Trabalho de Conclusão de Curso & 8 & 60 \\
\hline Trabalho de Conclusão de Curso & 8 & 60 \\
\hline Trabalho de Conclusão de Curso & 8 & 60 \\
\hline Trabalho de Conclusão de Curso & 8 & 60 \\
\hline Trabalho de Conclusão de Curso & 8 & 60 \\
\hline Trabalho de Conclusão de Curso & 8 & 60 \\
\hline Trabalho de Conclusão de Curso & 8 & 60 \\
\hline Estágio Supervisionado II - Inglês & 8 & 200 \\
\hline Sociologia da Educação & 8 & 60 \\
\hline Fundamentos de LIBRAS & 8 & 60 \\
\hline
\end{tabular}

${ }^{11}$ Tabela elaborada com base no mapa de ofertas de disciplinas para o curso de Letras Inglês no segundo semestre de 2013. 